$$
\begin{aligned}
& \text { بررسى تاريخ تكاملى زير كونهُ كمر كولى جنعلى در كوههاى زاكرس، ايران }
\end{aligned}
$$

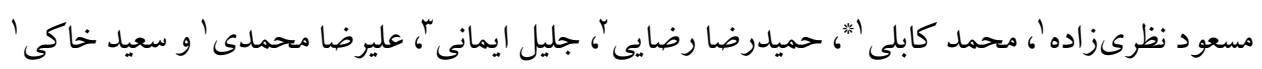

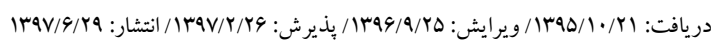

$$
\begin{aligned}
& \text { اكروه محيطزيست دانشكدة منابع طبيعى، يرديس كشاورزى و منابع طبيعى، دانشكاه تهران، كرج، ايران }
\end{aligned}
$$

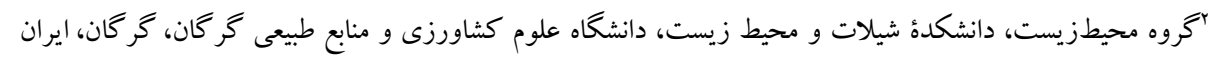

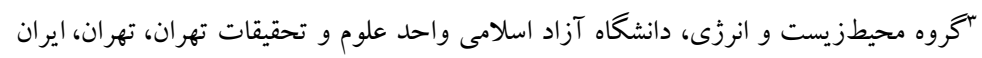

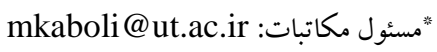

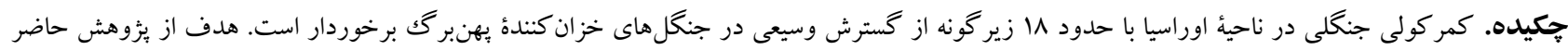

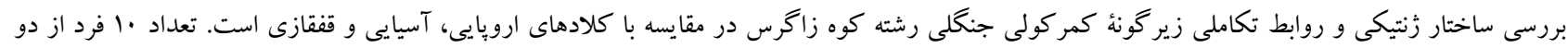

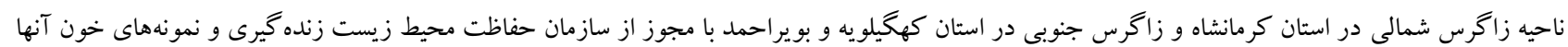

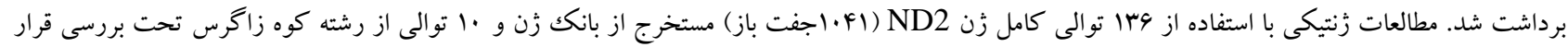

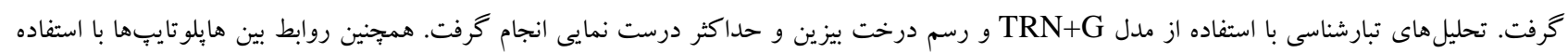

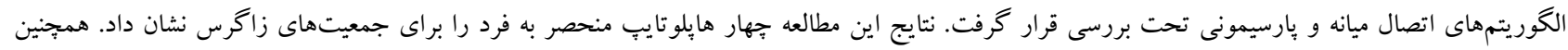

$$
\begin{aligned}
& \text { تحليلهاى تبارشناسى حاكى از آن بود كه جمعيتهاى زاكرس از تبار قفقازى تفكيك يذيذير است. نتايج آماره }
\end{aligned}
$$

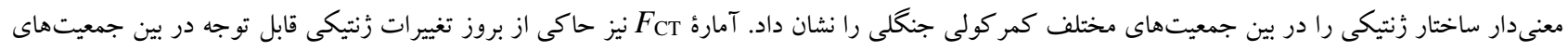

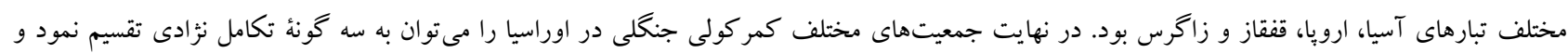

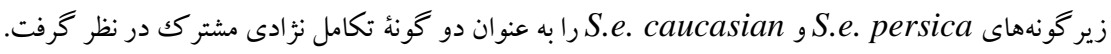

$$
\begin{aligned}
& \text { وازههاى كليدى. اوراسيا، روابط فيلوزنى، گونهُ تكامل نزادى، ميتو كندرى، نشانگر }
\end{aligned}
$$

\title{
Evolutionary history of subspecies of Eurasian nuthatches (Sitta europaea persica) from Zagros Mountains, Iran
}

\author{
Masoud Nazarizadeh ${ }^{1}$, Mohammad Kaboli ${ }^{*}$, Hamid Reza Rezaei², Jalil Imani ${ }^{3}$, Alireza \\ Mohmmadi ${ }^{1} \&$ Saeid Khaki ${ }^{1}$ \\ Received 10.01.2017/ Revised 16.12.2017/ Accepted 16.05.2018 / Published 20.09.2018
}

\begin{abstract}
${ }^{1}$ Department of Environmental Sciences, Faculty of Natural Resources, University of Tehran, Karaj, Iran ${ }^{2}$ Department of Environmental Sciences, Gorgan University of Agricultural Sciences and Natural Resources, Gorgan, Iran

${ }^{3}$ Department of Environment and Energy, Islamic Azad University, Tehran, Iran

Correspondent author: mkaboli@ut.ac.ir
\end{abstract}

\begin{abstract}
Sitta europaea, with 18 subspecies, has a wide distribution in deciduous forests of Eurasia. The aim of this study was to evaluate the taxonomic and phylogenetic relationships of this subspecies to European, Asian as well as Caucasian clades. 10 individuals of two populations from Zagros forests in Kermanshah and Kohgiluyeh and BoyerAhmad Provinces were captured with permission from Iran Department of Environment and their blood samples were collected. Furthermore, we used ND2 sequence data (1041 bp) for 136 sequences from GenBank and 10 sequences from Zagros Mts. Genetic variations and Genealogical analysis was calculated using complete ND2 gene sequence (1041bp) and TRN+G model, Bayesian trees and maximum likelihood, respectively. Median joining algorithm showed the relationships among haplotypes. We found four new haplotypes for the Zagros populations. Phylogenetic analysis indicated that Zagros populations were distinct from Caucasian clade. $F_{\text {ST }}$ statistical values, resulting from the analysis of molecular variance represented significant variations in genetic structure among Eurasian Nuthatch populations. Moreover, $F_{\mathrm{CT}}$ revealed significant variation among European, Asian and Caucasian clades. Our result suggests that Eurasian Nuthatch populations in Eurasia comprise three phylogenetic species, and likely biological species. However, the previous nomenclature subspecies, S.e. caucasian and S.e. persica, can be regarded as a common phylogenetic species.
\end{abstract}

Keywords. Eurasia, mitocondria, ND2 marker, phylogenetic relationship, phylogenetic species 
فرايندهاى جهش، انتخاب، مهاجرت و رانش زنتيكى منابع اصلى

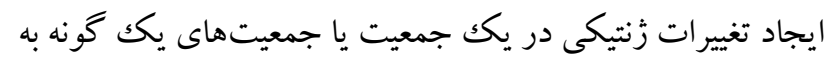

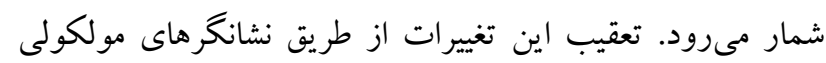

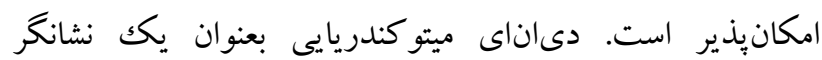

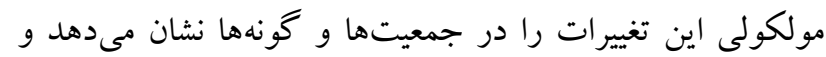

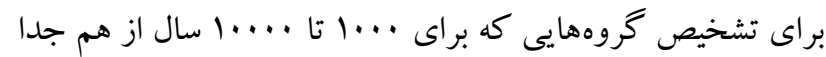

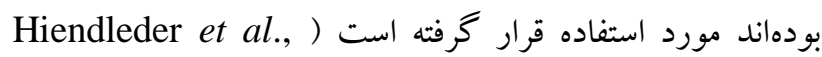
1998). ND2 ميتو كندريايى در راستو گنجشكشكلان داراى مرداي

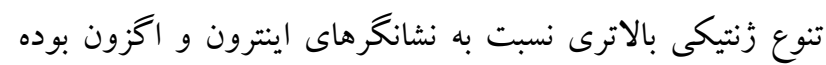

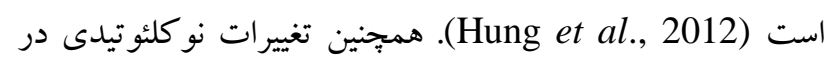
اين زن بيشتر تحت تأثير جريان زنى بوده است و ميزان كمترى به هـ

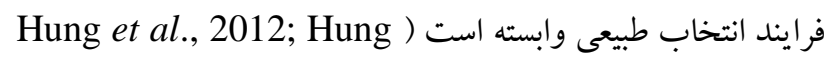
אI \& \&ink, 2014 كنجشكشكلان و DNA بار كدينك آنها به مراتب بهتر از زن زن

كزارش شده است (Nouri \& Aliabadian, 2014). COI مطالعات محققان در مورد جمعيتهاى كمر كولى جنكلى وجود ش

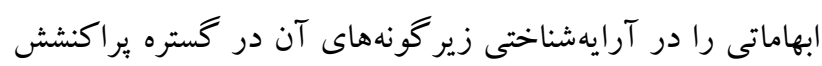

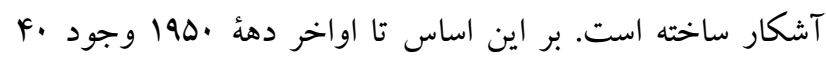

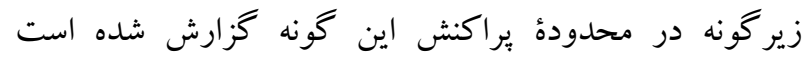

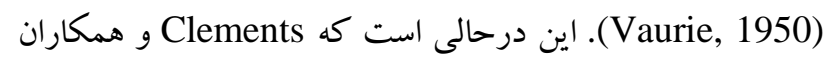

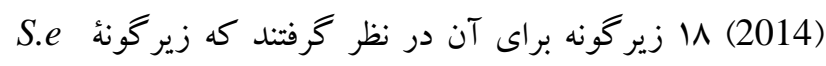
persica

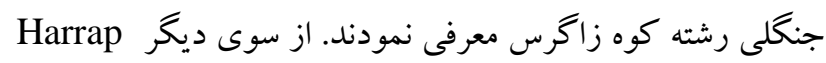

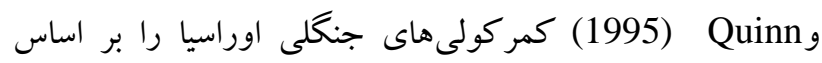
صفات ريختشناختى به سه دسته شامل caesia (زير تنه نخودى و زير گلو سفيد رنگ)، europaea (زيرتنه سفيد رنغك) و sinensis

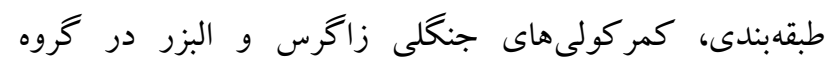

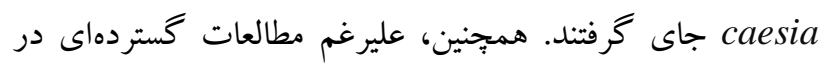

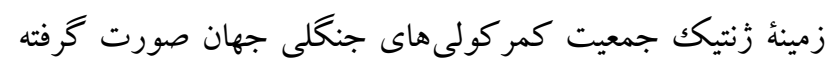
(Hung et al., 2012; Zink et al., 2006) اطلاعات زنتيكى در زمينهُ روابط خويشاوندى و ت تكاملى

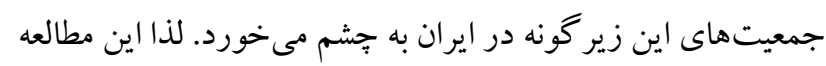

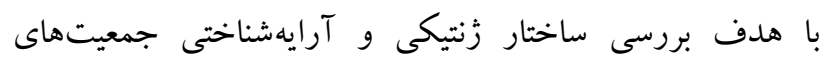

مقله

كمر كولى جنگلى (Sitta europaea Linnaeus, 1758)

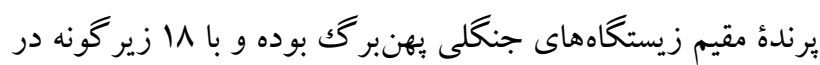

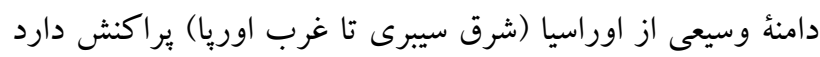
Matthysen \& Currie, 1996; Pravosudov, 1993; ) Clements et al., 2014 نقشى اساسى در طراحى راهبردهاى حفاظت از تنوع زيستى ايفا منى كند ) Bianconi et al., 2003; Matthysen \& Currie, 1996; Mortelliti et al., 2010; Zuckerberg et al., 2014). جراكه بهعنوان يكى گ خونة شاخص مىتواند وضعيت

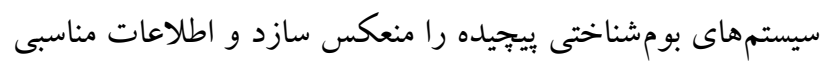
از آسيب جمعيتى نسبت به تكهشدگى زيستكاه فراهم سازد Baguette et al., 2012; Bianconi et al., 2003; ) ز (Matthysen et al., 1995; Mortelliti et al., 2010 طرفى هر گونه طرح حفاظتى براى گونهاى جندسنخى بايستى

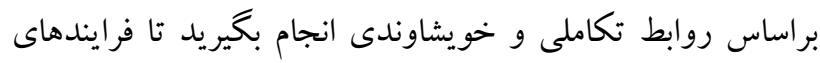

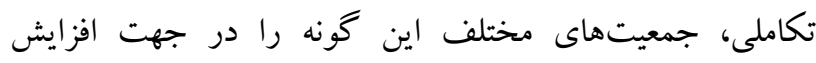

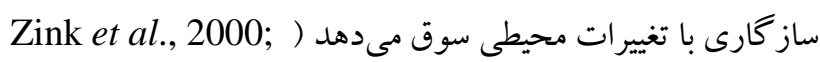
.(Hung et al., 2012 بهور كلى زير گونهها در صورتى كه نشاندهنده واحدهاى

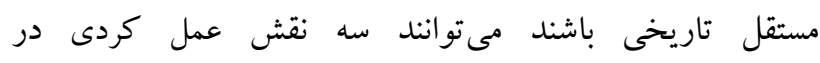
آرايهشناسى، تكامل و حفاظت از تنوع زيستى ايفا كند ( Zink,

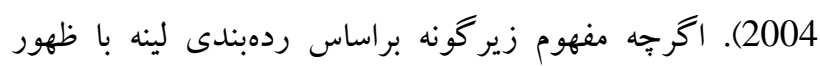

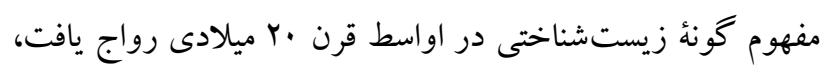

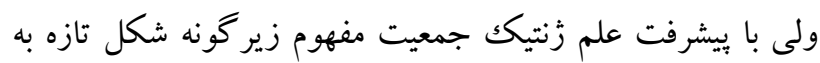
خود گرفت ) ز (Mulcahy, 2008 بدين ترتيب در سالهاى اخير مطالعات متعدد

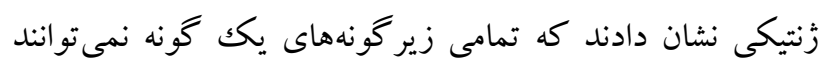

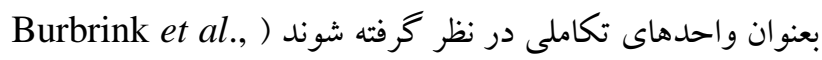
9 2000; Mulcahy, 2008 زير گونهاى :برند

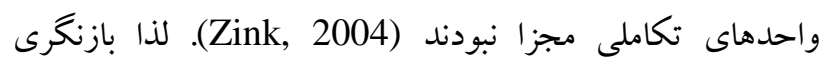

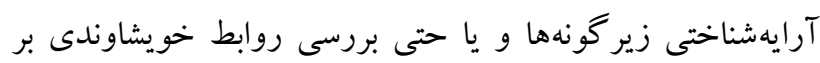

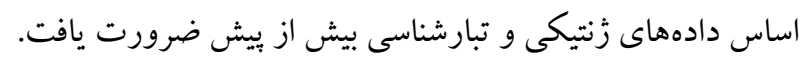


H1064 CTTTGAAGGC- و و آغازگر برگشت AAAT (Drovetski et al., 2004) CTTCGGTTTA

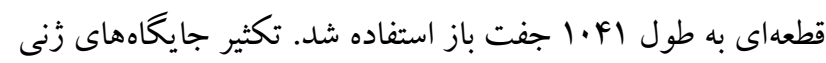

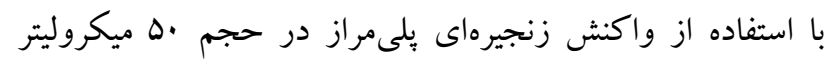
و شرايطى شامل يك ميكروليتر (TopTaq Master Mix Kit) DNA يكك ميكروليتر ييكومولار، 10X و ميكروليتر بافر آب دو بار تقطير تا رسيدن

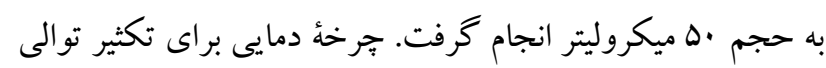

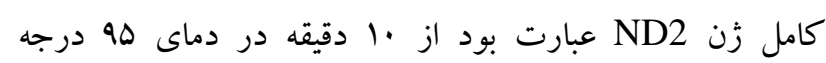

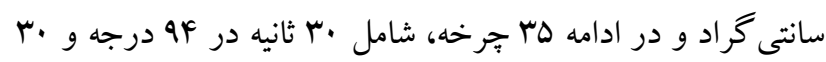

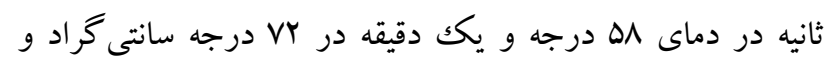

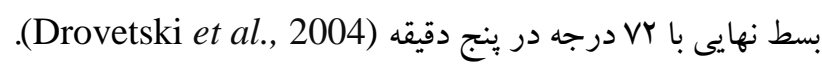

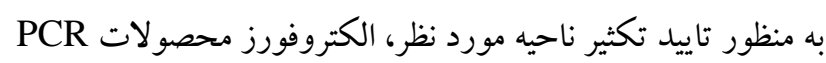
بر روى زل آكاروز r درصد با رنغك آميزى اتيديوم برومايد

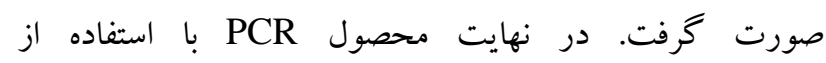
دستكاه 3730 Applied Biosystems 3730/ Bioneer و به دورت روش اتوماتيك سانگر توالى يابى شدند.

تجزيه وتحليل دادهها

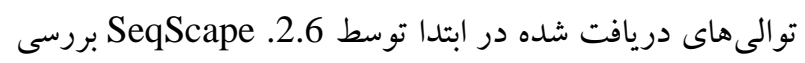

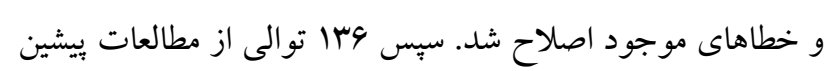
(Zink 2006; Hung et al., 2012) ثبت شده در بانكك زن DQ219639-DQ219772) دانلود شد أندان تا امكان انجام تجزيه و تحليلها مقايسهاى با ساير جمعيت هاى كونه مورد نظر در منطقه بالئارتيك فراهم شود. در نهايت

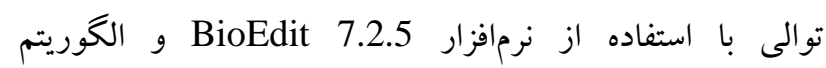

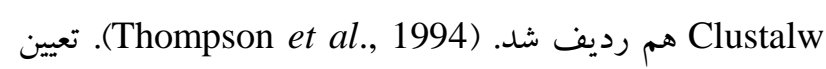
فاصلهُ زنتيكى بين جمعيتها توسط نرم افزار 5.3 MEGA و 5 و مدل

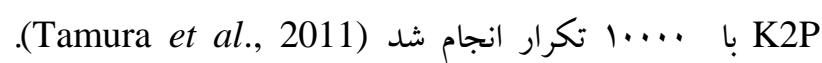

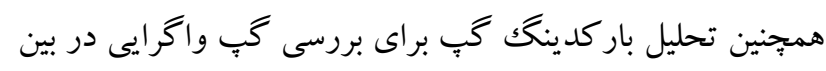

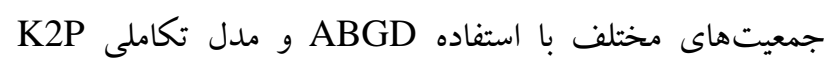
تخمين زده شد (Puillandre et al., 2011) قبل از آغاز تحليلهاى تبارشناسى، فرضية اشباع جايخزينى با استفاده از نرم افزار

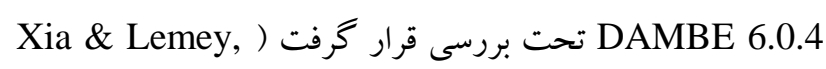
2009; Xia \& Xie, 2001
كمر كولى جنكلى زاگرس S.e. persica با استفاده از توالى كامل زن (1041bp) ND2 انجام شده است.

مواد و روشها كونة تحت مطالعه كمر كولى جنكلى، متوسط جثه با سر بزرگك، دم كوتاه و منقار قوى، ضخيم، به نسبت دراز و مستقيم است. نر و ماده تقريباً

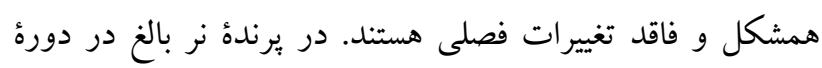

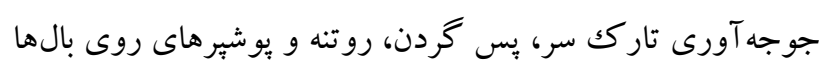

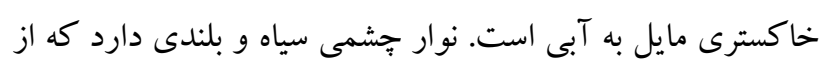

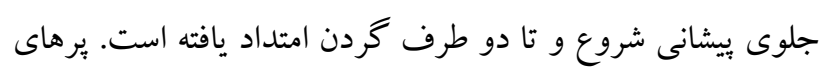

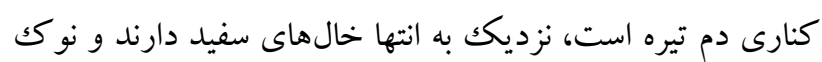

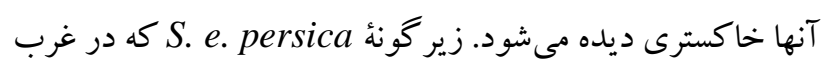

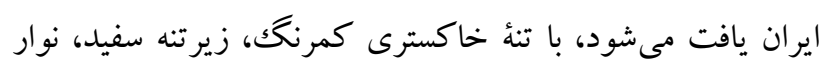

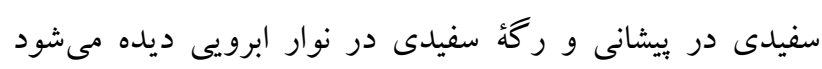
.(Kaboli et al., 2012) جمع آورى نمونه

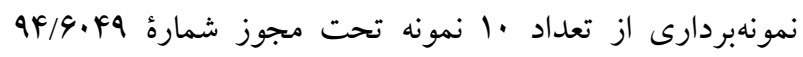

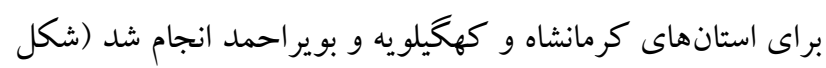

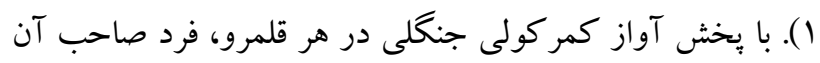

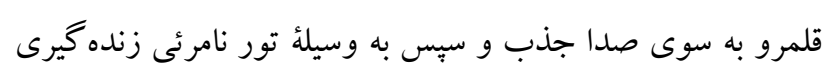

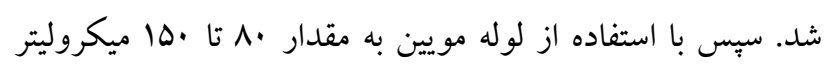

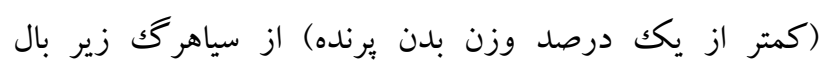

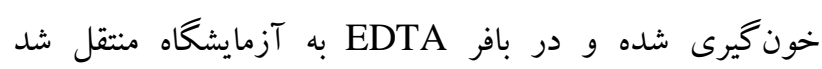

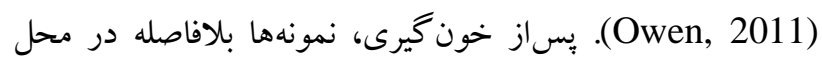

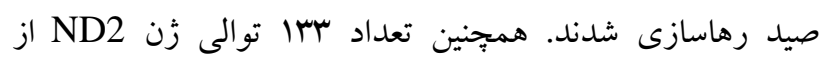

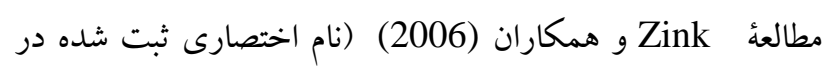

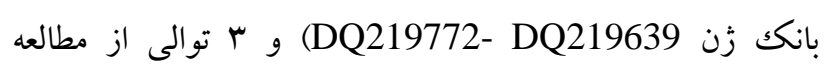

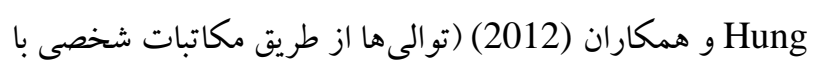
نو يسند كان دريافت شد) توسط بانكك زن دانلود شد و بدين ترتيب

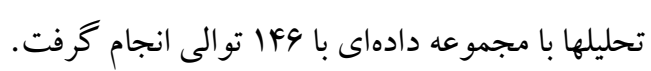

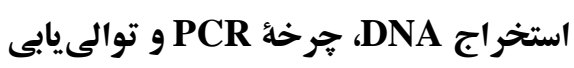

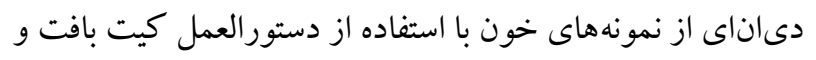

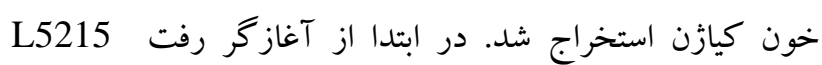
(Hackett, 1996) TATCGGGCCCATACCCCGA- 


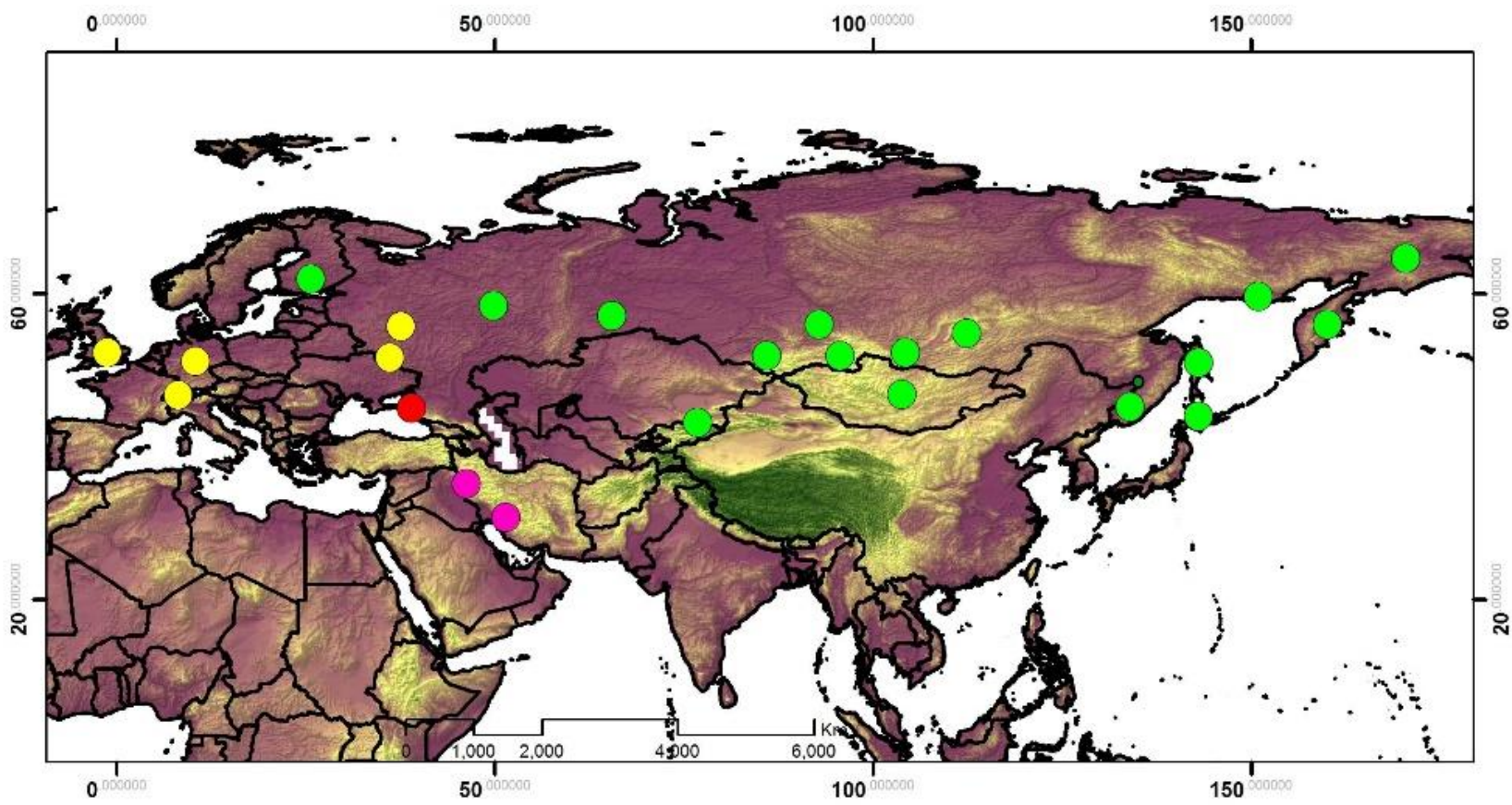

شكل ا- مناطق ير اكثش هايلوتايب هاى زن ND2 در اوراسيا، دايرههاى رنكى نشان دهندة كلادهاى شناخته شده (سبز = كلاد آسيا، قرمز = كلاد قفقاز، زردي كلاد

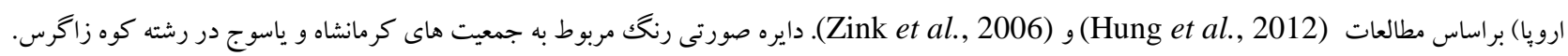

Fig. 1. Distribution of Eurasian Nuthatches ND2 haplotypes (Zink et al., 2006; Hung et al., 2012). Color of circle for lineages and haplotypes: Asian lineage (Green), Caucasian lineage (Red), and European lineage (Yellow). According to Hung et al. (2012) and Zink et al. (2006). Sample localities in Iran, including: Zagros forests (Kermanshah and Yasouj) (Pinkish circles).

استفاده شد (Ronquist \& Huelsenbeck, 2003). تحليلهاى

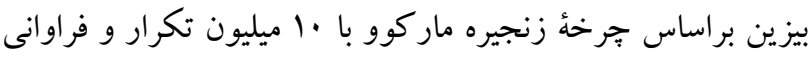

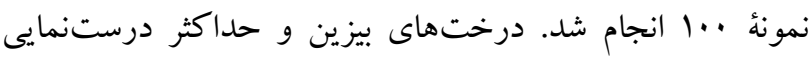

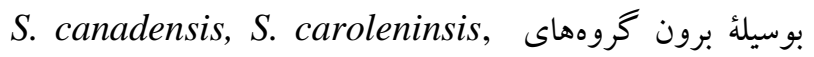
S. S. e. arctica و Sitta. pygmaea DQ219774.1, اختصارى ثبت شده در بانكك زن بهترتيب (DQ219776.1, EF108553.1 DQ219778.1 ايستايى و انحراف معيار درخت بيزين رسم شده در نرمافزار

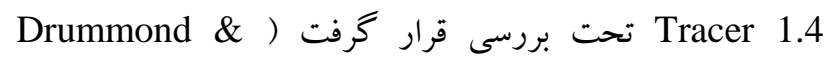

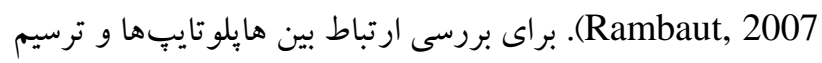

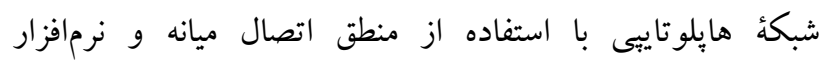

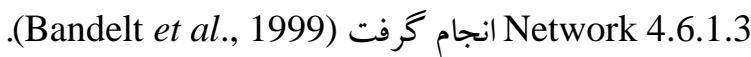

نتايج

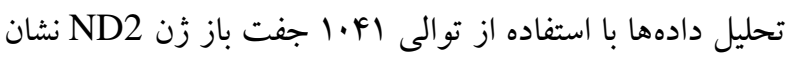

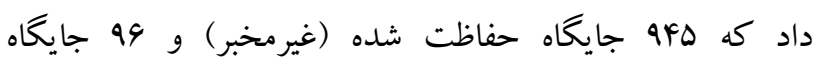
جندشكلى بوده كه شامل سَو جايكاه حاوى اطلاعات بِارسيمونى

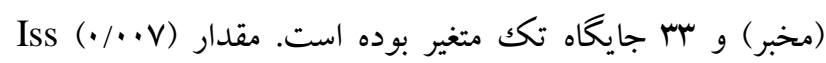

جند شكلى و نمودار خبراكنش ناهمخوان با استفاده از نرمافزار Librado \& Rozas, 2009) تخمين زده شد DNAsp 5.10 همجنين از نرمافزار Arlequin 3.5 براى تعيين تعداد شاخص تنوع

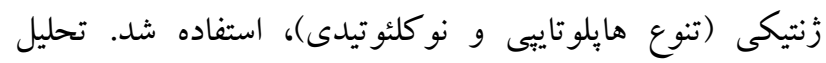
واريانس مولكولى (AMOVA) با استفاده از اين نرم افزار و با دو

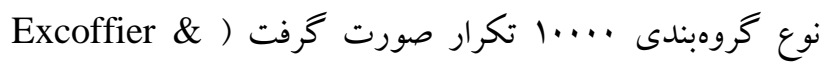
Schneider, 1999 ). در روش اول همه جمعيتهاى تحت

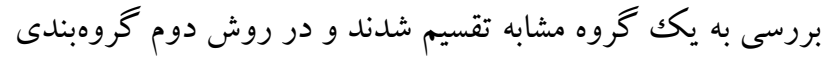
براساس تحليلهاى تبارشناسى و تبارهاى شناسايى شده انجام

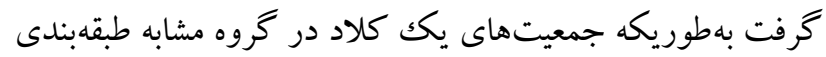

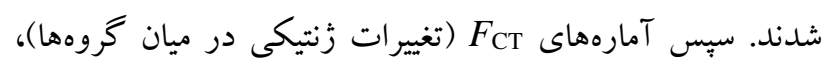

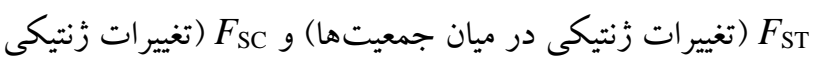
در ميان جمعيتهاى يكك گروه) تعيين شدند

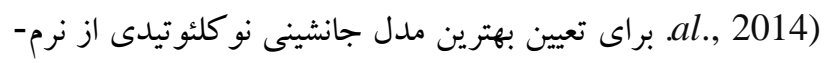
افزار DModelTest 2.1.3 استفاده شد (Darriba et al., 2012). سجّ با توجه به مدل انتخاب شده از نرمافزار 3.1 Phyml براى

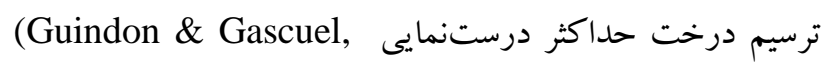

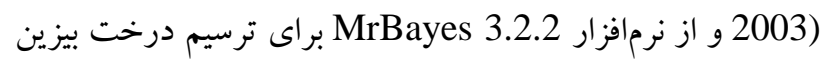


F در سطح خطاى ه • / معنى دار شدند. جدول ץ ميزان فاصلة

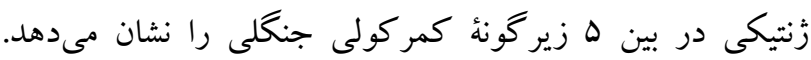

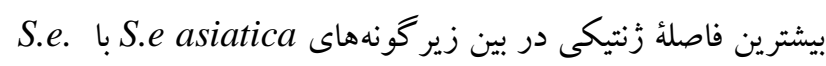

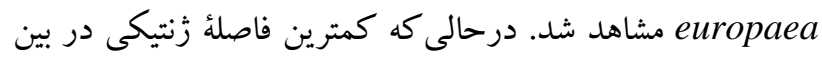
دو زير گونه S.e. persica asiatica به با S.e. caucasian بهست آمد. شكل 9، تحليل بار كدينگك در بين زير گونهاى مختلف كمر كولى جنكى را نشان مىدهد. نتايج

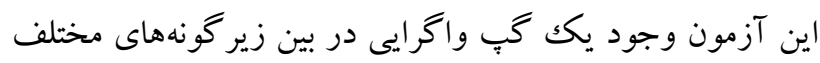

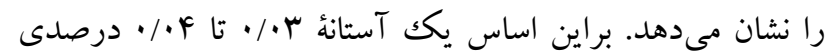

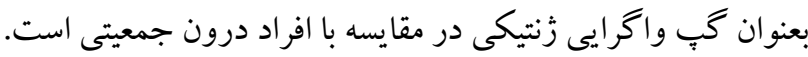

\section{بحث و نتيجه كيرى}

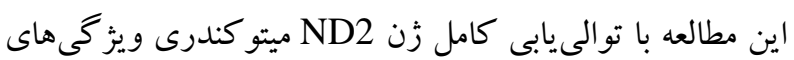

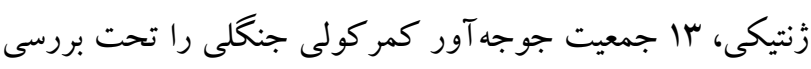

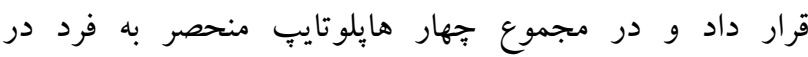

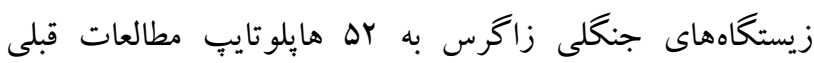
(Hung et al., 2012)

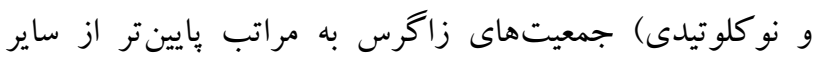

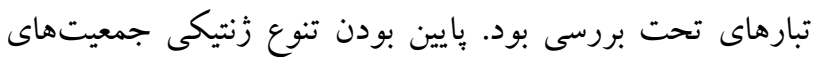

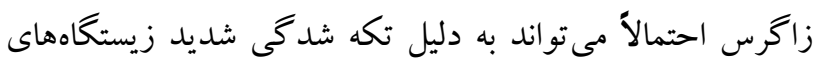

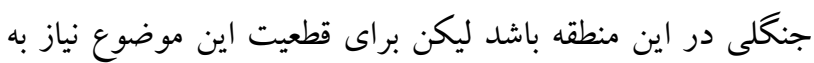

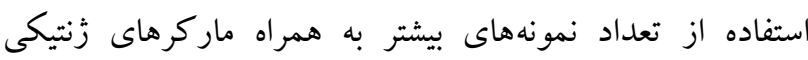
متفاوت (هستهاى و ميتو كندرى) است. همجنين تعداد اندك نمونه-

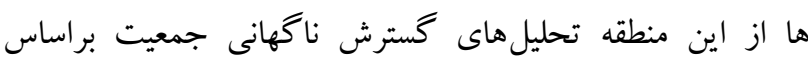

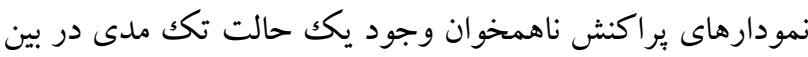

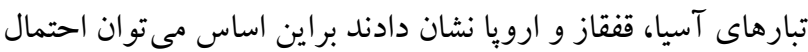
يكك گسترش ناكهانى جمعيتى در بين تبارهاى مذكور را استنباط

در يثزوهش صورت گرفته توسط Hung و همكاران (2012)

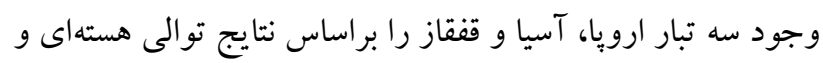

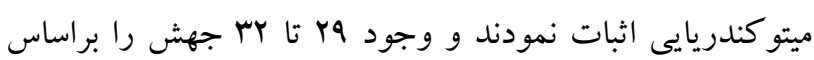
توالى كامل زن ND2 در بين سه تبار مذكور نشان دادند. تحليل

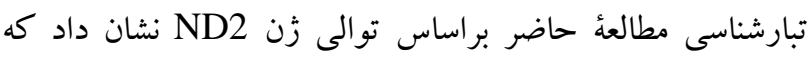

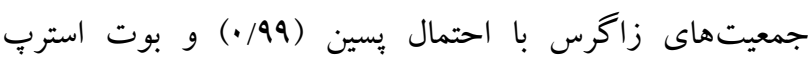

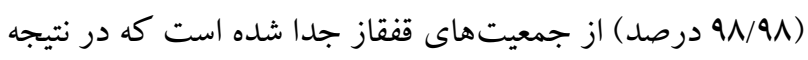

نسبت به Iss.c (•/V9I در تحليل اشباع جايكزينى كوجکك تر و

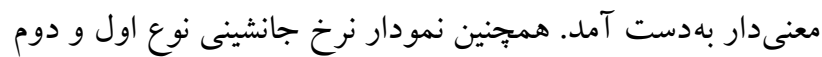

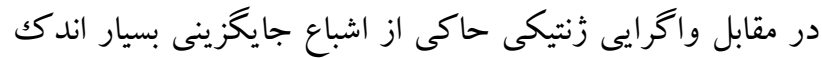

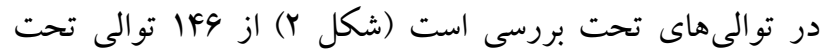

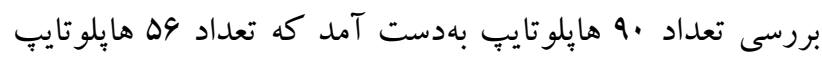
منحصر به فرد بودند. همجِنين از •ا توالى تحت بررسى مربوط به دو جمعيت از رشته كوه زاكرس (كرمانشاه و ياسوج)، تعداد جهار هايلو تايب شناسايى شد كه يك هإِلوتايب در بين اين دو جمعيت

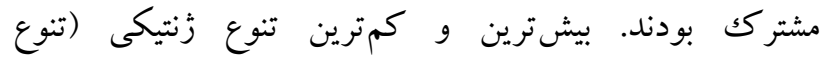

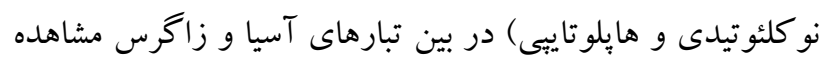

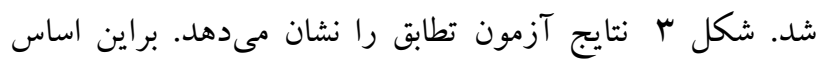

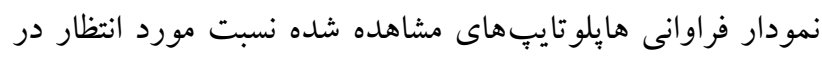

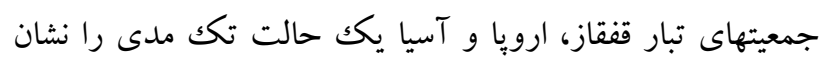

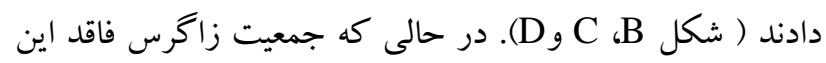
حالت تكك مدى بوده است ( شكلشماره شكل؟؟ آد). آزمون معيارهاى اطلاعات بيزين (BIC) و اطلاعات آكايكه TRN+G (G=/.91) نشان داد كه مدوان بهترين (AIC) مدل تكاملى نو كلئوتيدى براى توالىهاى مورد نظر شناسايى شد. مداد

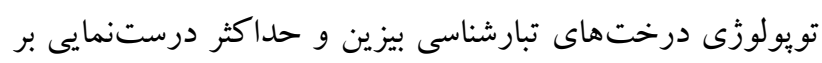

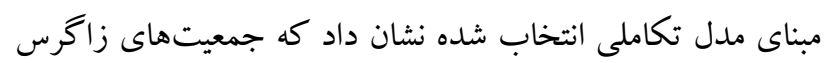

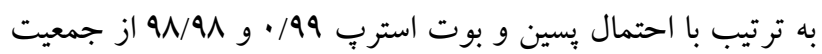

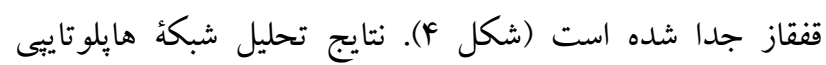
براساس اتصال ميانه نشان داد كه جمعيت هايى زاگرس تنها با بنج

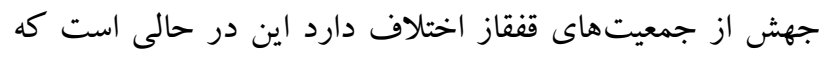

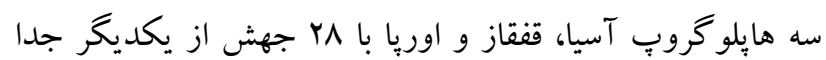
شدهاند (شكل ه). جدول r نتايج حاصل از تجزئ واريانس مولكولى (AMOVA)

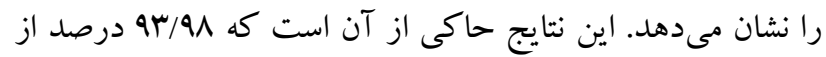

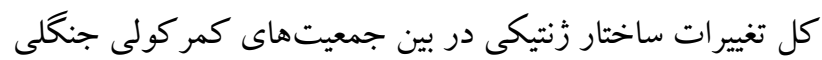

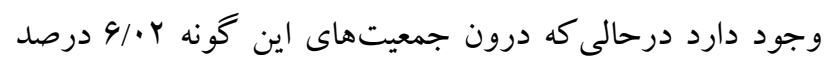

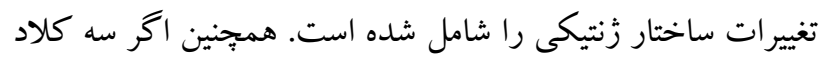
قفقاز، ارويا و آسيا در گروههاى مجزا طبقهبندى شوند، تغييرات

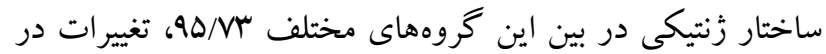

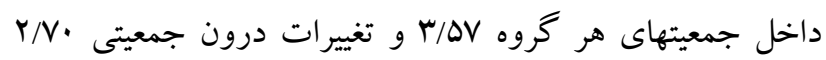

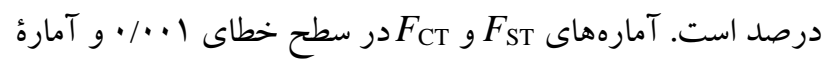




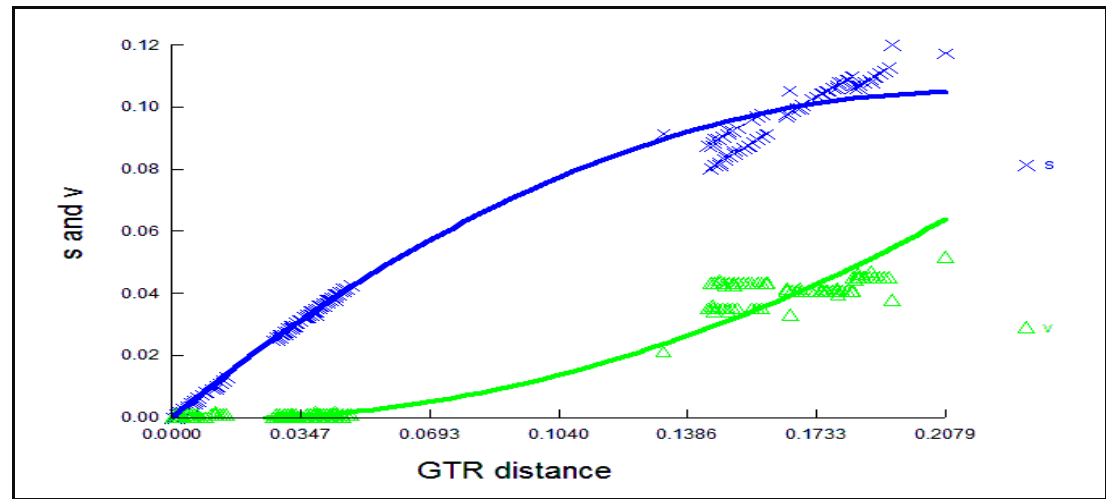

شكل r- بِلات جانشينى هاى نوع اول و دوم در مقابل واكرايى زنتيكى.

Fig. 2. Plotting the observed transitions and transversions against the genetic divergence.

جدول ا- ويزگى هاى زنتيكى تبارهاى تحت بررسى و شاخص تنوع زُنتيكى (Hd = تنوع هايلو تاييى، Pi= تنوع نو كلئو تيدى، n= تعداد نمونها، k= ميانكين تعداد

نو كلو تيدهاى مختلف).

Table 1. The genetic characteristics of lineage and genetic diversity index (Hd- haplotype diversity, Pi- nucleotide diversity, n: number of samples, K- The average number of different nucleotides).

\begin{tabular}{|c|c|c|c|c|c|}
\hline $\mathrm{k}$ & pi & $\mathrm{Hd}$ & $\mathrm{H}$ & $\mathrm{n}$ & تبار \\
\hline $1 / N r$ &.$/ .19$ & $\cdot / v \Delta$ & $r v$ & $1 . r$ & آسيا \\
\hline $1 / r V$ &.$/ \cdot I r$ & $\cdot N \cdot$ & $r$ & 11 & قفقاز \\
\hline.$/ 9$ & $\cdot / \cdots \Delta$ & $\cdot / \Delta r$ & r & 1. & زاكرس \\
\hline$Y / \cdot Y$ &.$/ .19$ & $\cdot / A V$ & 11 & r & ارويا \\
\hline
\end{tabular}

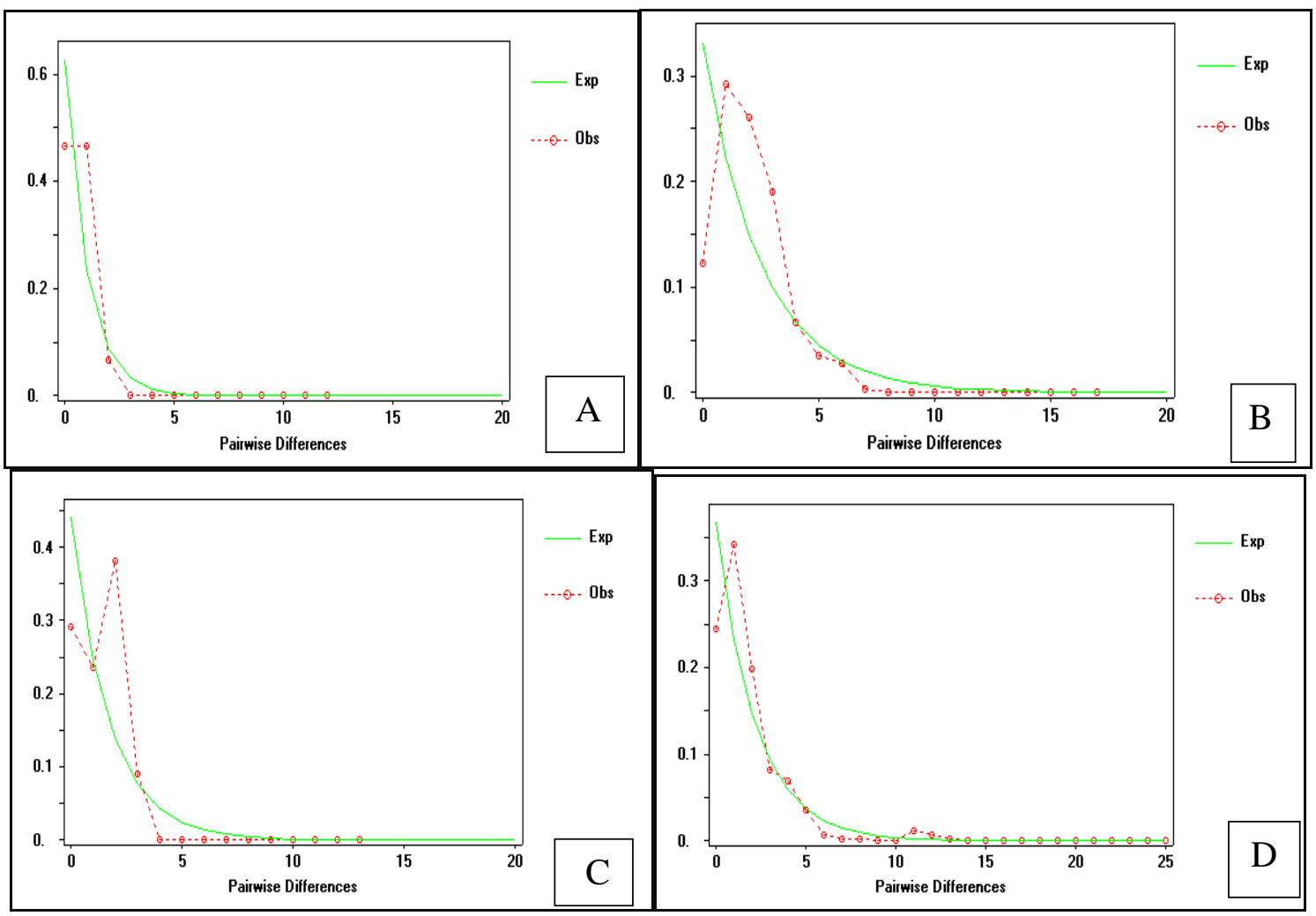

شكل سـ- نمودارهاى ير اكنش ناهمخوان براساس توالى كامل زن ND2. A : تبار زاكرس، B: تبار قفقاز، C: تبار ارويا و D: تبار آسيا. محور افقى تعداد نو كلئو تيدهاى مختلف در بين

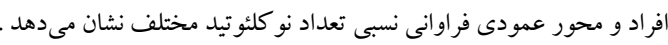

Fig. 3. Graphs of mismatch distribution based complete sequence ND2. A: Zagros lineage, B: Caucasian lineage, C: European lineage and D: Asian lineage. Horizontal axis is number of different nucleotides between individuals, and the vertical axis indicates the relative frequency of different nucleotide numbers. 


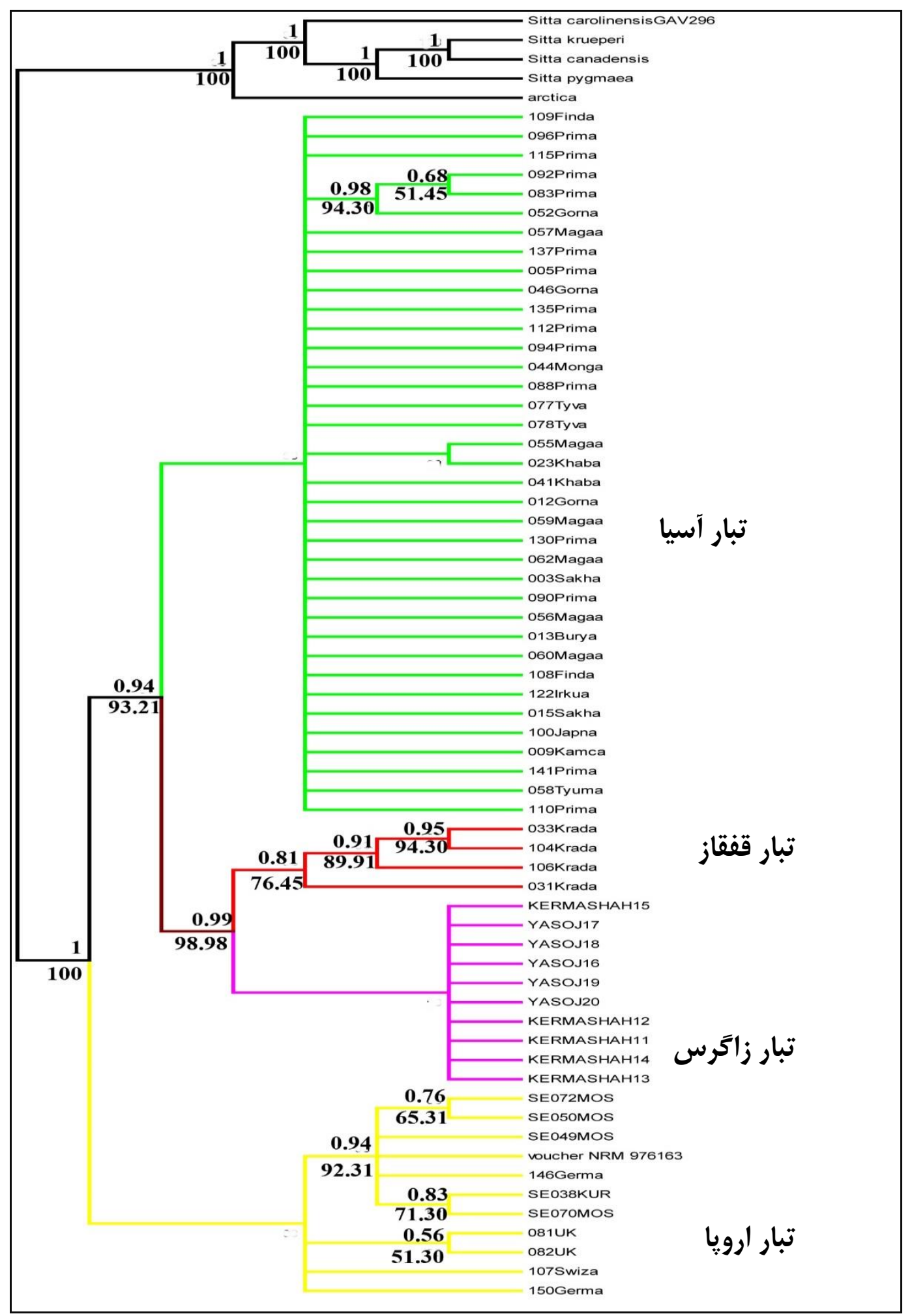

شكل ع- درخت تبارشناسى كمر كولى جنكلى در زيستخاههاى زاگرس با استفاده از دو روش بيزين و حداكثر درستنمايى (تويولوزى يكسان). اعداد بالا نمايانكر

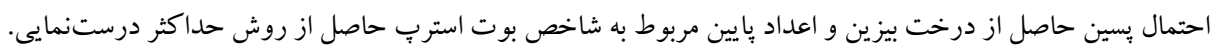

Fig. 4. Phylogenetic tree of Eurasian Nuthatches in habitat Zagros through two methods bayesian and maximum likelihood, with the values of top branches corresponding to posterior probabilities and the lower branches representing Bootstrap support. 


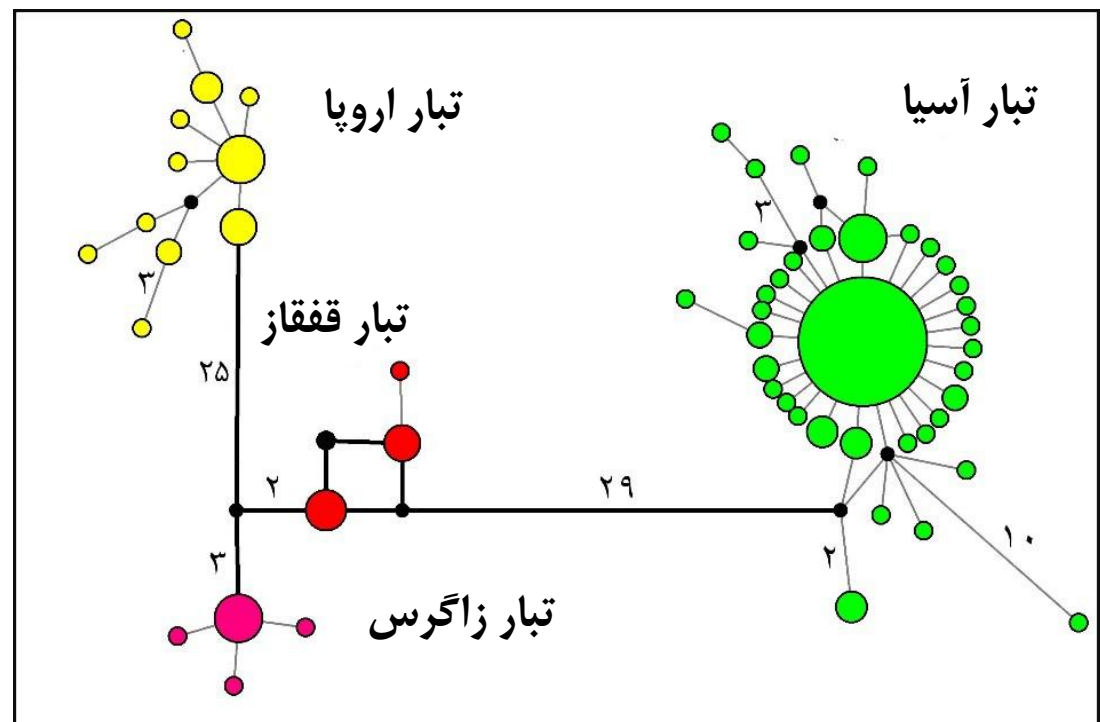

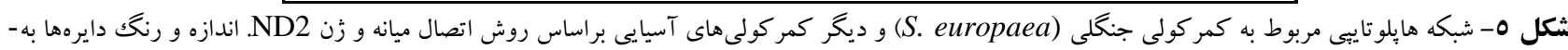

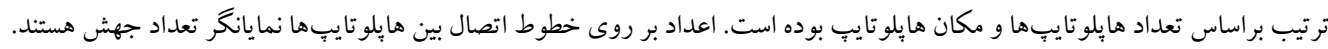

Fig. 5. Haplotype network (Median Joining network) of the Eurasian Nuthatch and other Eurasian Nuthatches, based on complete ND2 sequence. Size and color of circles represent the number and position of haplotypes respectively. The numbers above the connecting branches reflect the number of mutational steps joining the haplotypes.

$$
\begin{aligned}
& \text { جدول r- تجزية واريانس مولكولى (AMOVA) در بين جمعيتهاى كمر كولى جنكلى () در نظر گرفتن همة جمعيتها بعنوان يك گروه r) گروبندى } \\
& \text { جمعيت ها براساس كلادهاى مشخص شده در تحليلهاى تبارشناسى. }
\end{aligned}
$$

Table 2. Analysis of molecular variance (AMOVA) for four lineages of the Eurasian Nuthatch 1) considering all

\begin{tabular}{|c|c|c|c|c|}
\hline 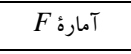 & درصد واريانس & مجموع مربعات & f.d. & منابع تغيير \\
\hline \multirow{3}{*}{$F_{\mathrm{ST}}=\cdot / 9 \mathrm{~F}^{* \mathrm{~s}}$} & $94 / 91$ & $9 \wedge \Delta / 19$ & ir & (1) بين جمعيتهاى مختلف \\
\hline & 91.4 & $99 / \mathrm{rV}$ & 1.9 & درون جمعيتها \\
\hline & & $1.01 / \Delta$. & $|r|$ & كل \\
\hline$F_{\mathrm{CT}}=\cdot / 99^{* * *}$ & $9 \Delta / N r$ & QFY/F. & $r$ & (r) بين گروههاى مختلف \\
\hline$F_{\mathrm{SC}}=\cdot / \pi r^{*}$ & $r / \Delta V$ & Fr/vA & 1. & بين جمعيتهاى داخل يك گروه \\
\hline \multirow[t]{2}{*}{$F_{\mathrm{ST}}=\cdot / 99^{* * *}$} & $r / v$. & $99 / \pi$. & 1.9 & بين افراد درون يكك جمعيت \\
\hline & & $1.01 / 0$. & $|r|$ & 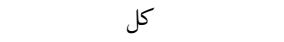 \\
\hline
\end{tabular}
populations as a unified group and 2) grouping of populations based on identified lineages by phylogenetic analysis.

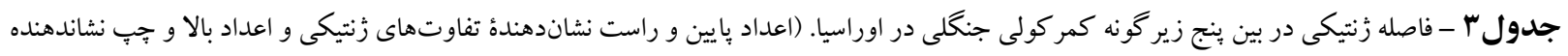

$$
\text { انحر اف معيار هستند). }
$$

Table 3. Genetic distance among five subspecies of $S$. europaea in Eurasia (the below and right numbers represent the

\begin{tabular}{|c|c|c|c|c|c|c|}
\hline .1 .94 & .1 .94 & .1 .49 & .1 .94 & & IV & europaea \\
\hline $.1 . .4$ &.$/ \cdots \Delta$ & .1 .04 & &.$/ . \mathrm{rq}$ & 1. & persica \\
\hline$\cdot \cdots \Delta$ & $\%$ & &.$/ .44$ &.$/ . \mathrm{rq}$ & 11 & caucasian \\
\hline$\cdot / \cdots$ & &.$/ 41$ & . &.$/ .49$ & Fa & asiatica \\
\hline &.$/ \cdot 1$ &.$/ r$. & . &.$/ \cdot \Lambda$ & is & amurensis \\
\hline
\end{tabular}
genetic differences and the upper and left numbers represent the standard deviation).

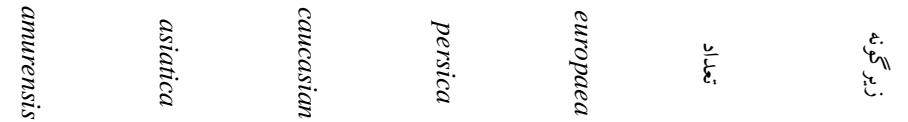




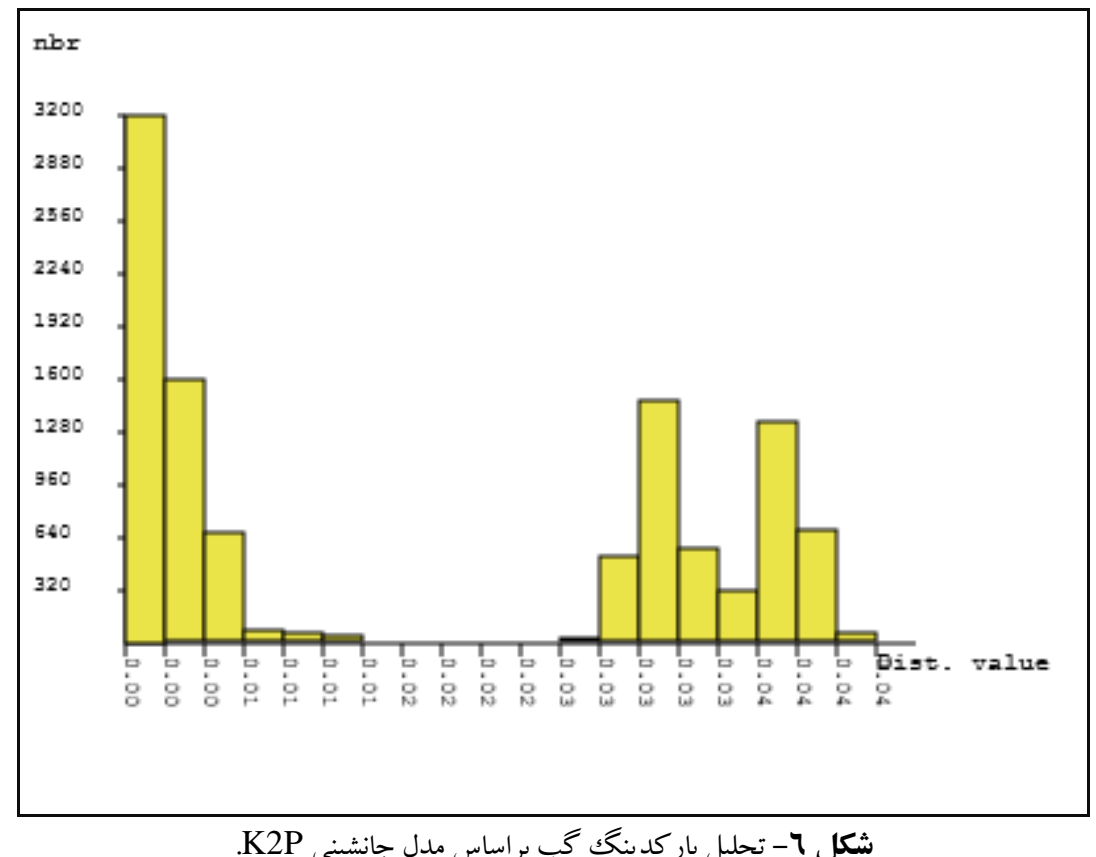

Fig. 6. The Barcoding gap analysis based on K2P substitution model.

(2014; Zink, 2004

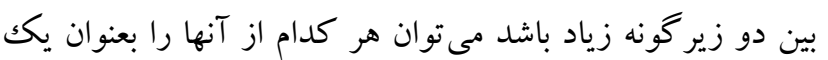

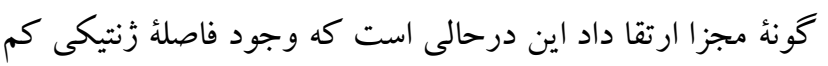

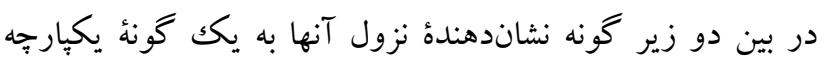

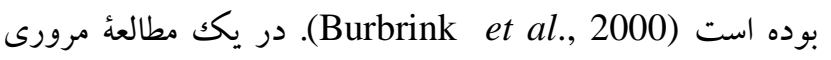
Torstrom

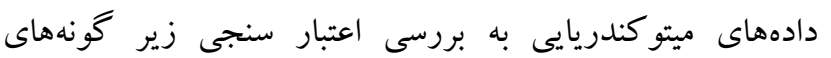

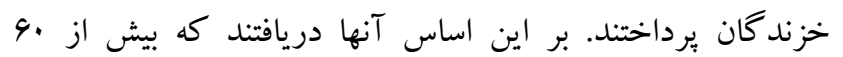

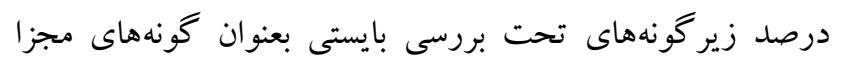

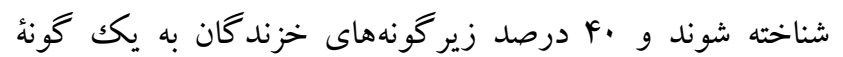

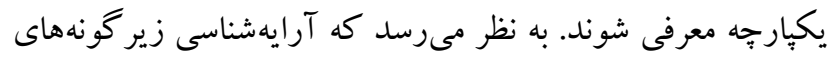

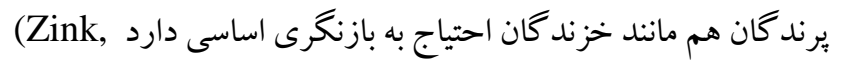

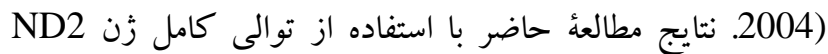

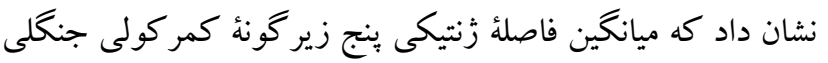

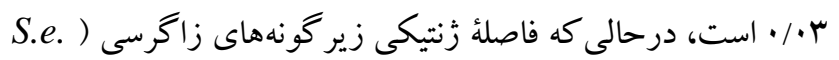
(persica شد كه نشاندهندة عدم تفكيك زُنتيكى قابل توجه بين اين دو

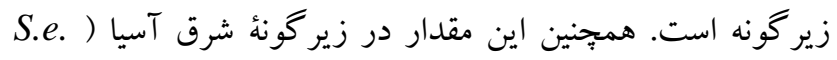
(S.e. asiatica) با زير گونه شرق و مركز آسيا (amurensis ا••• بهدست آمد. لذا بر اين اساس بايستى اعتبار سنجى

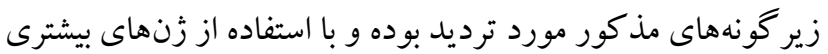

مىتوان جمعيت هاى زاخرس را بعنوان تبار مجزايى از تبار قفقاز

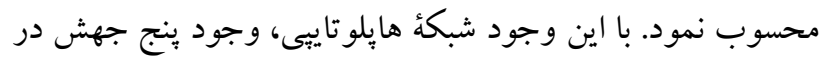
بين جمعيتهاى زاكرس و قفقاز را نشان ميدهد كه اين ميزان جهش در مقايسه با تعداد جهش هاى جدايى تبارهاى آسيا، ارويا و ورئ

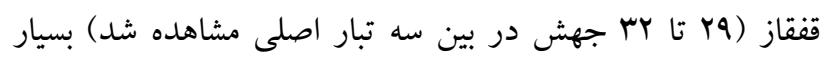
كمتر بوده است. نتايج تحليل واريانس مولكولى (AMOVA)

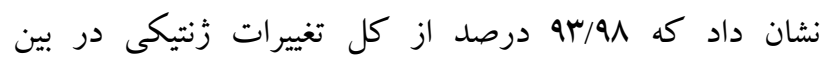
جمعيتهاى مختلف كمر كولى جنكلى وجود دارد كه عمدهترين

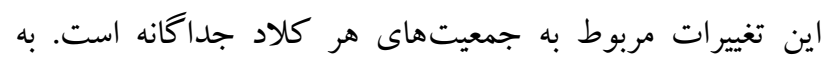
عبارت ديخر، جمعيت هاى هر كلاد داراى كمترين درصد تغييرات در ساختار زنتيكى هستند ولى با جمعيت هاى كلاد ديخر بيشترين

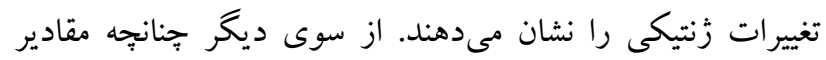
شاخصهاى تثبيت حاصل از تحليل AMOVA بين · تا هـ/.

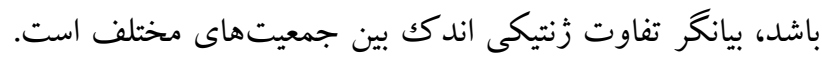
بر اين اساس، مقادير بين هـ/• تا هץ/• نشاندهنده تفاوت متوسط و

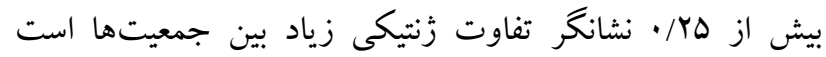

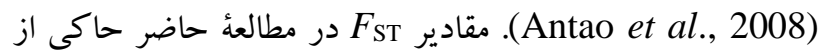
بروز يك تفاوت زنتيكى معنادار در بين جمعيتهاى مختلف كمر كولى جنگلى است.

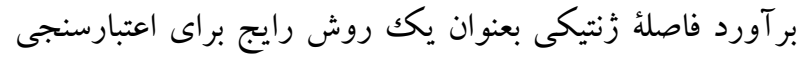

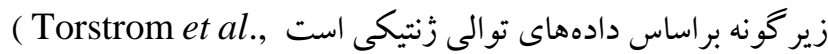




\section{REFERENCES}

Antao, T., Lopes, A., Lopes, R. J., Beja-Pereira, A. and Luikart, G. 2008. LOSITAN: a workbench to detect molecular adaptation based on a F ST-outlier method. BMC Bioinformatics 9: 323-333.

Ashton, K.G. and de Queiroz, A. 2001. Molecular systematics of the western rattlesnake, Crotalus viridis (Viperidae), with comments on the utility of the D-loop in phylogenetic studies of snakes. - Mol. Phyl. Evol. 21: 176-189.

Avise, J.C. and Wollenberg, K. 1997. Phylogenetics and the origin of species. - PNATLASCI, 94: 7748-7755.

Avise, J.C. 1996. Introduction: the scope of conservation genetics. In Conserv. Genetics (pp. 1-9). Springer US.

Avise, J.C. 2000. Phylogeography: the history and formation of species: Harvard Univ. Press, Cambridge, MA. Pp 447.

Baguette, M., Legrand, D., Fréville, H., Van Dyck, H., Ducatez, S., Clobert, J., Baguette, M. and Bullock, J. 2012. Evolutionary ecology of dispersal in fragmented landscape. - Disp. Ecolo. Evol. 19: 381-391.

Bandelt, H.J., Forster, P. and Röhl, A. 1999. Medianjoining networks for inferring intraspecific phylogenies. - Mol. Biol. Evol. 16: 37-48.

Bianconi, R. Battisti, C., and Zapparoli, M. 2003. Pattern of richness, abundance and diversity of four interior bird species in a hilly landscape in Central Italy: a contribution to assess their sensitivity to habitat fragmentation. - J. Mediterranean Ecol. 4: 37-44.

Burbrink, F.T., Lawson, R. and Slowinski, J.B. 2000. Mitochondrial DNA phylogeography of the polytypic North American rat snake (Elaphe obsoleta): a critique of the subspecies concept. - Evol. 54: 2107-2118.

Clements, J., Schulenberg, T., Iliff, M., Robertson, D., Fredericks, T., Sullivan, B. and Wood, C. 2014. The eBird/Clements checklist of birds of the world: Version 6.9. Available at http://www. birds. cornell. edu/clementschecklist/downloadable-clements-checklist.

Darriba, D. and Posada, D. 2014. jModelTest 2.0 Manual v0.1.1.

Drovetski, S.V., Zink, R.M., Fadeev, I.V., Nesterov, E. A., Koblik, E.A., Red'kin, Y. and Rohwer, S. 2004. Mitochondrial phylogeny of Locustella and related genera. - J. Avian Biol. 35: 105-110.

Drummond, A.J. and Rambaut, A. 2007. BEAST: Bayesian evolutionary analysis by sampling trees. BMC J. Evol. Biol. 7: 214-221.

Excoffier, L. and Schneider, S. 1999. Why huntergatherer populations do not show signs of Pleistocene demographic expansions. - P. Natl. Acad. Sci. 96: 10597-10602.

Fu, Y.X. 1997. Statistical tests of neutrality of mutations against population growth, hitchhiking and background selection. - Genetics, 147: 915-925.

González-Varo, J.P., López-Bao, J.V. and Guitián, J. 2008. Presence and abundanceof the Eurasian nuthatch Sitta europaea in relation to the size, isolation and the
تحت بررسى مجدد قرار بكيرد. از سوى ديخر نتايج آزمون بار كدينك كب يكك آستانه سه تا جهار درصدى را براى واكرايى فراد بين زير گونهاى و يكك واكرايى يك درصد براى افراد درون جمعيتى نشان داد (شكل 9). اين درحالى است كه واكرايى زنتيكى زير گونهاى مذكور در آستانهُ افراد درون جمعيت قرار گرفت. لذا شايد بتوان كمركولى جنكلى زاگرس را بعنوان جمعيت جدا شدهاى از زير گونه قفقازى دانست. ليكن براى اعتبار سنجى مستدل زير گونهاى مذكور بايستى از تعداد بيشترى زنهاى ميتو كندريايى و هستهاى استفاده شود. از آنجايى كه تمامى زير گونها به ندرت نشاندهنده تاريخ تكاملى مستقلى هستند، لذا متخصصان معتقدند كه همه زيرگ گونها نمى توانند به عنوان واحدهاى مديريتى مجزا جهت برنامههاى (Zink, 2004; Zink et al., حفاظت در نظر كرفته شوند (2000. بهطوريكه با مشخص كردن هر كلاد بعنوان يكك واحد تكاملى، نقش اساسى در طراحى برنامههاى حفاظتى ايفا كند

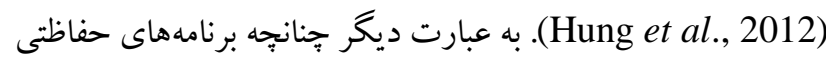
براى هر واحد تكاملى به طور مجزا انجام گيرد، تاريخ تكاملى جمعيتهاى هر واحد در جهت افزايش ساز گارى گونه نسبت به تغييرات محيطى حفظ مىشود. بر اين اساس . Hung et al. 2012) واحدهاى تكاملى كمر كولى جنگلى را به سه دسته آسيا، ارويا و قفقاز طبقهبندى نموده و هر واحد تكاملى را بعنوان كونهاى تكاملى نزادى و حتى كونههاى زيستشناختى معرفى نمودند. نتايج مطالعه حاضر نشان داد كه زير گونه S.e. persica در جنگل هاى زاگرس در تبارى مجزا از تبار قفقاز است كه با زيركونه S.e.caucasian اساس يزٔوهش حاضر، مىتوان جمعيتهاى كمر كولى جنگلى در زيستگاههاى زاگرس را بعنوان جمعيت جدا شدهاى از زيركونه كمر كولى جنشلى قفقازى استنباط نمود.

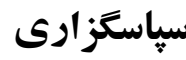
ز تمامى محيطبانان فداكار سازمان حفاظت محيطزيست كه طى لـ مراحل نمونهبردارى از هيج كمكى دريغ نكردند، سياسگز ارى مى شود. همجينين از دكتر Chih-Ming Hung براى فراهم نمودن برخى دادهها تشكر مى شود. 
intensity of management of chestnut woodlands in the NW Iberian Peninsula. - Landscape. Ecol. 23: 79-89.

Guindon, S. and Gascuel, O. 2003. A simple, fast, and accurate algorithmto estimate large phylogenies by maximum likelihood. - Syst. Biol. 52: 696-704.

Hackett, S.J. 1996. Molecular phylogenetics and biogeography of tanagers in the genus Ramphocelus (Aves). - Mol. Phyl. Evol. 5: 368-382.

Harrap, S. and Quinn, D. 1995. Chickadees, tits, nuthatches \& treecreepers Princeton University Press, Princeton. Pp 464.

Hiendleder, S., Lewalski, H., Wassmuth, R. and Janke, A. 1998. The complete mitochondrial DNA sequence of the domestic sheep (Ovis aries) and comparison with theother major ovine haplotype. - J. Mol. Evol. 47: 441-448.

Hrbek, T., Farias, I.P. Crossa, M. Sampaio, I. Porto, J.I. and Meyer, A. 2005. Population genetic analysis of Arapaima gigas, one of the largest freshwater fishes of the Amazon basin: implications for its conservation. Anim. Conserv. 8: 297-308.

Huelsenbeck, J.P. and Ronquist, F. 2001. MRBAYES: Bayesian inference of phylogenetic trees. Bioinformatics 17: 754-755.

Hung, C.M. and Zink, R.M. 2014. Distinguishing the effects of selection from demographic history in the genetic variation of two sister passerines based on mitochondrial-nuclear comparison. - J. Hered. 113: 4251.

Hung, C.M., Drovetski, S.V. and Zink, R.M. 2012. Multilocus coalescent analysis support a mtDNA-based phylogeographic history for a wide spread palearctic passerine bird, Sitta europaea. - Evol. 66: 2850-2864.

Kaboli, M., Aliabadian, M., Tohidifar, M., Musavi, S. B., Hashemi, A. and Roselaar, C.C. 2012: Atlas of birds of Iran. Tehran: Department of Environment of Iran. Pp: 628.

Khalilipour, O., Rezaei, H.R., Alizadeh Shabani, A., Kaboli, M. and Ashrafi, S. 2014. Genetic structure and differentiation of four populations of Afghan Pika (Ochotona rufescens) in Iran based on mitochondrial cytochrome b gene. - Zool. Midd. East. 60: 288-298.

Librado, P. and Rozas, J. 2009. DnaSP v5: a software for comprehensive analysis of DNA polymorphism data. Bioinformatics 25: 1451-1452.

Matthysen, E., Adriaensen, F. and Dhondt, A.A. 1995. Dispersal distances of nuthatches, Sitta europaea, in a highly fragmented forest habitat. - Oikos 1: 375-381.

Matthysen, E. and Currie, D. 1996. Habitat fragmentation reduces disperser success in juvenile nuthatches Sitta europaea: evidence from patterns of territory establishment. - Ecography 19: 67-72.

Mayr, E. 1970. Populations, species, and evolution: an abridgment of animal species and evolution. Harvard University Press. Pp: 240.

Mortelliti, A., Fagiani, S., Battisti, C., Capizzi, D. and Boitani, L. 2010. Independent effects of habitat loss, habitat fragmentation and structural connectivity on forest-dependent birds. - Divers. Distrib. 16: 941-951.

Mulcahy, D.G. 2008. Phylogeography and species boundaries of the western North American Nightsnake
(Hypsiglena torquata): revisiting the subspecies concept. - Mol. Phyl. Evol.46: 1095-1115.

Nouri, S. and Aliabadian, M. 2014. Performance of two mitochondrial genes, ND2 and COI to identify Passerin birds of Khorasan Province. - 18th National and 6th International Congress of Biology in Iran.

Owen, J.C. 2011. Collecting, processing, and storing avian blood: a review. - J. Field. Ornithol. 82: 339-354.

Pravosudov, V.V. 1993. Breeding biology of the Eurasian Nuthatch in northeastern Siberia. - The Wilson Bulletin 475-482.

Puillandre, N., Macpherson, E., Lambourdière, J., Cruaud, C., Boisselier-Dubayle, M. C. and Samadi, S. 2011. Barcoding type specimens helps to identify synonyms and an unnamed new species in Eumunida Smith, 1883 (Decapoda: Eumunididae). - Inverteber. Syst. 25: 322-333.

Ramírez-Soriano, A., Ramos-Onsins, S.E., Rozas, J., Calafell, F. and Navarro, A. 2008. Statistical power analysis of neutrality tests under demographic expansions, contractions and bottlenecks with recombination. - Genetics 179: 555-567.

Ramos-Onsins, S.E. and Rozas, J. 2002. Statistical properties of new neutrality tests against population growth. - Mol. Biol. Evol. 19: 2092-2100.

Ronquist, F., and Huelsenbeck, J.P. 2003. MrBayes 3: Bayesian phylogenetic inference under mixed models. - Bioinformatics 19: 1572-1574.

Tajima, F. 1989. Statistical method for testing the neutral mutation hypothesis by DNA polymorphism.Genetics 123: 585-595.

Tamura, K., Peterson, D., Peterson, N., Stecher, G., Nei, M. and Kumar, S. 2011. MEGA5: molecular evolutionary genetics analysis using maximumlikelihood, evolutionary distance, and maximum parsimony methods. - Mol. Biol. Evol. 28: 2731-2739.

Thompson, J.D., Higgins, D.G., and Gibson, T.J. 1994. CLUSTAL W: improving the sensitivity of progressive multiple sequence alignment through sequence weighting, position-specific gap penalties and weight matrix choice. - Nucleic Acids. Res. 22: 4673-4680.

Torstrom, S.M., Pangle, K.L. and Swanson, B.J. 2014. Shedding subspecies: The influence of genetics on reptile subspecies taxonomy. - Mol. Phyl. Evol. 76: 134-143.

Van Langevelde, F., Schotman, A., Claassen, F. and Sparenburg, G. 2000. Competing land use in the reserve site selection problem. - Landscape. Ecol. 15: 243-256.

Vaurie, C. 1950. Notes on some Asiatic nuthatches and creepers. - The American Museum of Natural history city of New York. pp: 1-10.

Wang, L.Y., Ikeda, H., Liu, T.L., Wang, Y.J. and Liu, J.Q. 2009. Repeated range expansion and glacial endurance of Potentilla glabra (Rosaceae) in the Qinghai-Tibetan Plateau. - J. Integ. Plant Biol. 51: 698-706.

Xia, X. and Lemey, P. 2009. Assessing substitution saturation with DAMBE. The phylogenetic handbook: a practical approach to DNA and protein phylogeny. Cambridge University Press 2: 615-630. 
Xia, X. and Xie, Z. 2001. DAMBE: Software package for data analysis in molecular biology and evolution. - $\mathbf{J}$. Hered. 92: 371-373.

Yu, F., Li, S., Kilpatrick, W.C., McGuire, P.M., He, K., and Wei, W. 2012. Biogeographical studyof plateau pikas Ochotona curzoniae (Lagomorpha, Ochotonidae). - Zool. Sci. 29: 518-526.

Zink, R.M., Barrowclough, G.F., Atwood, J.L. and Blackwell- Rago, R.C. 2000. Genetics, taxonomy, and conservation of the threatened California gnatcatcher. Conserv. Biol. 14: 1394-1405.

Zink, R.M. 2004 The role of subspecies in obscuring avian biological diversity and misleading conservation policy. - Biol. Sci. 271: 561-564.

Zink, R.M., Drovetski, S.V. and Rohwer, S. 2006. Selective neutrality of mitochondrial ND2 sequences, phylogeography and species limits in Sitta europaea. Mol. Phyl. Evol. 40: 679-686.

Zuckerberg, B., Carling, M., Dor, R., Ferree, E., Spellman, G. and Townsend, A. 2014. Differential relationships between habitat fragmentation and within-population genetic diversity of three forestdwelling birds. - BioRxiv 1: 14-40.

\section{$* * * * *$}

How to cite this article:

Nazarizadeh, M., Kaboli, M., Rezaei, H.R., Imani, J., Mohmmadi, A. and Khaki, S. 2018. Evolutionary history of subspecies of Eurasian nuthatches (Sitta europaea persica) from Zagros Mountains, Iran. - Nova Biologica Rep. 2018: 155-167.

نظرىزاده، م.، كابلى، م.، رضايى، ح.ر.، ايمانى، ج.، محمدى، ع. و و

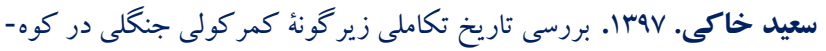

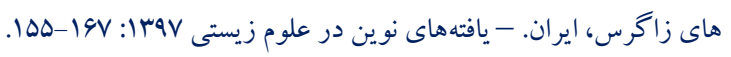

